\title{
Job burnout and organizational justice among medical interns in Shanghai, People's Republic of China
}

This article was published in the following Dove Press journal:

Advances in Medical Education and Practice

26 August 2015

Number of times this article has been viewed

\author{
Wei-Min Jin' \\ Ying Zhang ${ }^{2}$ \\ Xiao-Ping Wang' \\ 'Department of Neurology, Shanghai \\ General Hospital, ${ }^{2}$ Department \\ of Neuroscience, Shanghai Renji \\ Hospital, Shanghai Jiao Tong University \\ School of Medicine, Shanghai, People's \\ Republic of China
}

Background: New challenges are occurring in the medical education in Mainland China, and the main risk is the loss of excellent physician candidates. This is due to lack of respect; a large, strong labor force; relatively low remuneration; unstable relationships between patients and doctors; pressures from the public media; and the possible existence of organizational injustice within the hospital. The study reported here looked at one of the in-hospital risks, psychological job burnout and organizational justice, to identify the possible internal cause-effect relationship at the two major general hospitals both affiliated to Shanghai Jiao Tong University School of Medicine.

Objective: The aim of the reported study was to analyze the related factors associated with job burnout in Chinese medical interns in Shanghai and to provide some suggestions to better their occupational development.

Methods: A total of 135 medical interns were investigated and assessed by the Organizational Justice Scale and the Maslach Burnout Inventory - General Survey.

Results: There was a statistically significant negative correlation between organizational justice and job burnout ( $r=-0.298, P=0.000$ ), suggesting the existence of job burnout among the participant interns. In particular, emotional exhaustion and cynicism were statistically more significant; the comparison between the $\mathrm{N}$ group (from Nanjing) and $\mathrm{S}$ group (Shanghai) showed significant difference in participation and reduced professional efficacy $(P<0.05)$, with reduced professional efficacy in $\mathrm{N}$ group more significant than in $\mathrm{S}$ group, and participation in $\mathrm{S}$ group more significant than in $\mathrm{N}$ group.

Conclusion: Job burnout existed among Chinese medical interns, and was associated with fewer complaints and lower professional efficacy. Organizational justice should be promoted more, and school authorities should pay more attention to outside "non-home" interns. Finally, it is essential that the medical interns themselves establish reasonable judgment of their valuable profession.

Keywords: medical education, Chinese, psychology, emotional exhaustion, professional efficacy

\section{Introduction}

The pioneering scholars Maslach and Leiter defined "job burnout" as comprehensive symptoms including emotional exhaustion, cynicism, and reduced professional efficacy $^{1}$ that occur when health care practitioners in the helping professions cannot respond effectively under the pressure arising from ongoing work. During past 30 years, job burnout has received widespread attention, and it has been studied in community education, public service, the military, management, medical practice, and other fields. ${ }^{2-4}$ Having been established over 20 years ago and cited by more than
Correspondence: Xiao-Ping Wang Department of Neurology, Shanghai General Hospital, Shanghai Jiao Tong University School of Medicine, 100 Haining Road, Shanghai 200080, People's Republic of China Fax +86 21 6324375

Email wangxp@ustc.edu 
500 studies, the Maslach Burnout Inventory - General Survey (MBI-GS) is considered the gold standard questionnaire in the area of burnout research. It has been used throughout the USA and Europe, as well as recently in Asia, South America, and Africa. Although substantial research achievements have been obtained, and prevention and intervention measures have been established abroad, research in this area has been relatively less active in Mainland China. Current studies indicate that job burnout occurs frequently in professional practitioners who deal with other persons, such as teachers and health care practitioners. ${ }^{4,5}$ Therefore, it is important to study job burnout among health care professionals.

In recent years, many Chinese domestic researchers have conducted various studies of nurses. For example, Li and $\mathrm{Liu}^{4}$ performed a comprehensive study of job burnout in Chinese nurses, and suggested potential methods for the prevention of, and intervention in, job burnout. The authors of the study reported here are also aware of a few studies of physicians, whose job needs good interpersonal skills and deals with consistent pressure. ${ }^{6}$ Worldwide, many doctors experience occupational burnout - a deterioration of body, spirit, and will; some of them lose momentum and fall far short of achieving their academic potential. A study of faculty members at four US medical schools found that $20 \%$ had significant levels of depressive symptoms, with even higher levels in younger faculty members. ${ }^{7-9}$ The study presented here also examined whether medical intern types and the different universities were associated with organizational commitment, job involvement, and job satisfaction, by means of an Organizational Justice Scale. As yet, there is very little research focusing on job burnout among Chinese medical interns. This is likely due to the fact that interns are at the bottom of the Chinese medical hierarchy. In essence, a medical intern is a transitional position in medical education. It is worthwhile for the public to pay attention to these temporary medical groups. ${ }^{7}$

\section{Methods}

\section{Participants}

The authors received written informed consent from every participant. The ethics committee of Shanghai Jiao Tong University School of Medicine approved the study (author XPW received a grant, number 2008013). Using the cluster sampling method, 145 medical interns were initially recruited from Shanghai First People's Hospital and Shanghai Renji Hospital, both affiliated to Shanghai Jiao Tong University School of Medicine. The questionnaires administered were confidential and all participants were assured that no individual would be identified. Ten participants were excluded due to incomplete data, so the actual number of subjects was 135 (Figure 1). They were divided into $\mathrm{N}$ group and $\mathrm{S}$ group, with $\mathrm{N}$ group and S group comprising 41 (30.4\%) and 94 (69.6\%) interns from Nanjing Medical University and Shanghai Jiao Tong University, respectively. This study was performed from March to May 2008, after the interns had received 8-10 months of medical training.

\section{Evaluation scales}

\section{Organizational Justice Scale}

The Organizational Justice Scale ${ }^{5}$ was divided into distributive justice and procedural fairness sections. "Distributive justice", using a questionnaire prepared by Marshfield, ${ }^{8}$ refers to the results obtained by the perception of fairness, including five categories. "Procedural fairness", which included participation and complaint mechanisms, refers to the perception of the fairness of procedures and methods which determine the results, including employee involvement, consistency, impartiality, and rationality. "Participation" refers to employee participation in daily work, and this was assessed with four questions. "Complaint mechanisms", also assessed by four questions, refers to employee challenge of supervisors and decision-making units. The questionnaire uses a 5 -point scale ranging from 1 to 5 points: 1 stands for

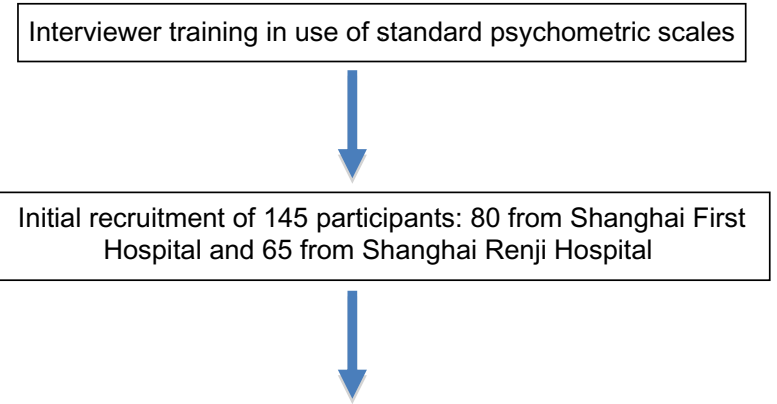

Data on 135 participants statistically analyzed (ten excluded due to having incomplete data)

Scores of Organizational Justice Scale and job burnout questionnaire analyzed by bivariate correlation analysis, partial correlation analysis, regression analysis layer by layer, and independent samples $t$-test

Figure I Flowchart of the overall project. 
"Totally disagree"; 5 stands for "Completely agree". The higher the score, the higher the level of agreement, equity (which is proportional to the psychological scores) will increase. The Organizational Justice Scale has been used in some Chinese institutions, such as the Chinese University of Hong Kong, Hangzhou University, and the Institute of Psychology of Chinese Academy of Science, has been proved to have good reliability and validity, and the internal consistency coefficient scores among the dimensions of both organizational justice and job burnout ranged between 0.81 and 0.94 , significantly higher than the recommended score of $0.70 .^{2,5}$

\section{Job burnout formal questionnaire}

The job burnout scale adopted was the internationally frequently used MBI-GS. ${ }^{1,2}$ A Chinese version of the questionnaire was translated by four experts independently and was finalized by team discussion. A modified version of the MBI-GS - Chinese was drafted, then the draft was translated from Chinese to English by two native English-speaking experts, in order to prevent the loss of information from the original English version. ${ }^{5}$ The questionnaire MBI-GS consists of three subscales: motional exhaustion (five questions), cynicism (four questions), and reduced professional efficacy (six questions). The questionnaire includes a 7-point system from 0 to 6 points: 0 stands for "Never", 6 stands for "Very frequent". The first two subscales represent the positive scoring method, with the greater the average subscale, the stronger the degree of job burnout. The latter subscale is scored by the reverse method, with the smaller the average, the stronger the degree of job burnout. Many studies have confirmed that the MBI-GS series scale has good reliability and validity in the populations of Mainland China. ${ }^{2,5}$ The internal consistency coefficients found for the three dimensions of emotional exhaustion, cynicism, and reduced professional efficacy are $0.88,0.83$, and 0.82 , respectively. ${ }^{2}$

\section{Statistical analysis}

All data were analyzed using SPSS software (v 11.0), with the mean determined and bivariate correlation, partial correlation, and linear regression analyses made.

\section{Results}

A total of 145 individuals were surveyed, with 135 valid questionnaires returned and analyzed, and the effective rate was $93.1 \%$. The subjects comprised $69(51.1 \%)$ females and $66(48.9 \%)$ males.
To determine the correlation between organizational justice and job burnout, bivariate correlation analysis was performed. Organizational justice and job burnout were negatively correlated with very high statistical significance ( $r=-0.298, P<0.001)$. Further, the effect of organizational justice on job burnout was analyzed using partial correlation analysis to obtain the two related variables. Table 1 shows the partial correlation coefficient of distributive justice and emotional exhaustion with an $r$-value of $-0.218(P=0.011)$, indicating a negative correlation of statistical significance. The partial correlation coefficient of complaint mechanisms and emotional exhaustion was $-0.195(P=0.024)$ - another negative correlation with statistical significance. Distributive justice, participation, and complaint mechanisms were shown to have a statistically significant negative correlation with cynicism, with the partial correlation coefficient $-0.273(P=0.001),-0.275(P=0.001)$, and $-0.293(P=0.001)$, respectively.

\section{Comparison of $\mathrm{N}$ group and $\mathrm{S}$ group}

To understand the differences between $\mathrm{N}$ group (Nanjing) and S group (Shanghai) in terms of organizational justice and job burnout, linear regression analysis was performed. Significant difference was defined as $P \leq 0.05$. Distributive justice and participation in $\mathrm{N}$ group was significantly higher than in $\mathrm{S}$ group, and there was significant difference $(P=0.021)$ in participation (Table 2). There was no significant difference in complaint mechanisms between $\mathrm{N}$ group and $\mathrm{S}$ group. There was also no significant difference in motional exhaustion or cynicism between $\mathrm{N}$ group and $\mathrm{S}$ group, but reduced professional efficacy was significantly lower in $\mathrm{N}$ group than in $\mathrm{S}$ group $(P=0.013)$ (Tables $2-4)$. In addition, emotional exhaustion was more significant in $\mathrm{N}$ group than in $\mathrm{S}$ group, and cynicism was more significant in $\mathrm{S}$ group than in $\mathrm{N}$ group (Tables 3 and 4).

Table I Correlation analysis of individual dimensions of organizational justice and job burnout $(n=135)$

\begin{tabular}{|c|c|c|c|c|c|c|}
\hline \multirow[t]{2}{*}{$\begin{array}{l}\text { Job burnout/ } \\
\text { organizational } \\
\text { justice }\end{array}$} & \multicolumn{2}{|c|}{$\begin{array}{l}\text { Emotional } \\
\text { exhaustion }\end{array}$} & \multicolumn{2}{|c|}{ Cynicism } & \multicolumn{2}{|c|}{$\begin{array}{l}\text { Reduced } \\
\text { professional } \\
\text { efficacy }\end{array}$} \\
\hline & $r$ & $P$ & $r$ & $P$ & $r$ & $P$ \\
\hline $\begin{array}{l}\text { Distributive } \\
\text { justice }\end{array}$ & -0.218 & $0.011 *$ & -0.273 & $0.001 * *$ & -0.009 & 0.922 \\
\hline Participation & -0.131 & 0.130 & -0.275 & $0.00 I^{* *}$ & 0.040 & 0.646 \\
\hline $\begin{array}{l}\text { Complaint } \\
\text { mechanisms }\end{array}$ & -0.195 & $0.024 *$ & -0.293 & $0.00 I^{* *}$ & 0.028 & 0.746 \\
\hline
\end{tabular}

Notes: $* P<0.05 ; * * P<0.01$ (only item of reduced professional efficacy scored reversely). 
Table 2 Multiple linear regression analysis of intern job burnout (N/S groups)

\begin{tabular}{|c|c|c|c|c|c|}
\hline Dependent variable & Independent variable & Mean & Standard error & $\boldsymbol{F}$ & $P$ \\
\hline \multirow[t]{6}{*}{$\mathrm{N} / \mathrm{S}$ groups } & Distributive justice & $|3.65|$ & 6.447 & 2.51 & 0.09 \\
\hline & Participation & 12.453 & 5.549 & 5.23 & $0.021^{*}$ \\
\hline & Complaint mechanisms & 11.480 & 5.828 & 1.93 & 0.13 \\
\hline & Emotional exhaustion & 13.382 & 5.153 & 2.11 & 0.11 \\
\hline & Cynicism & 9.780 & 4.425 & 3.01 & 0.075 \\
\hline & Reduced professional efficacy & 21.674 & 4.756 & 5.96 & $0.013^{*}$ \\
\hline
\end{tabular}

Note: $* P<0.05$.

Abbreviation: N/S, Nanjing and Shanghai.

\section{Discussion}

\section{Main findings}

The subjects of this study were the medical interns. They worked at two university hospitals in Shanghai, trained by a combination of clinical theory and practice. Correlation analysis between organizational justice and job burnout indicated a negative correlation with statistical significance, which corresponds with Maslach's observation that unfairness is a very important factor in burnout. ${ }^{1}$

This study suggests that organizational justice and job burnout are statistically significantly correlated. In addition, partial correlation analysis showed that distributive justice has a significant correlation with emotional exhaustion. Similarly, complaint mechanisms has a significant correlation with emotional exhaustion. Complaint mechanisms can also lead to emotional exhaustion. In addition, the various dimensions of organizational justice have an impact on cynicism.

\section{Comparison of two schools (from Nanjing and Shanghai)}

Professional efficacy was significantly reduced in $\mathrm{N}$ group than in $\mathrm{S}$ group. This indicates that the medical students of $\mathrm{N}$ group, who had received their primary medical education in Nanjing city followed by intern training in Shanghai, have less sense of accomplishment than the medical students who

Table 3 Correlation analysis of individual dimensions of organizational justice and job burnout $(n=42)$ from Nanjing school

\begin{tabular}{|c|c|c|c|c|c|c|}
\hline \multirow[t]{2}{*}{$\begin{array}{l}\text { Job burnout/ } \\
\text { organizational } \\
\text { justice }\end{array}$} & \multicolumn{2}{|c|}{$\begin{array}{l}\text { Emotional } \\
\text { exhaustion }\end{array}$} & \multicolumn{2}{|c|}{ Cynicism } & \multicolumn{2}{|c|}{$\begin{array}{l}\text { Reduced } \\
\text { professional } \\
\text { efficacy }\end{array}$} \\
\hline & $r$ & $P$ & $r$ & $P$ & $r$ & $P$ \\
\hline $\begin{array}{l}\text { Distributive } \\
\text { justice }\end{array}$ & -0.382 & $0.014^{*}$ & -0.264 & 0.095 & -0.260 & 0.100 \\
\hline Participation & -0.155 & 0.334 & -0.206 & 0.197 & -0.018 & 0.913 \\
\hline $\begin{array}{l}\text { Complaint } \\
\text { mechanisms }\end{array}$ & -0.438 & $0.004^{*}$ & -0.546 & $0.000 *$ & -0.020 & 0.903 \\
\hline
\end{tabular}

Note: $* P<0.05$. were educated solely in Shanghai (S group). This may be due to different educational institutions and educational systems, along with the need for the $\mathrm{N}$ group students to adjust to the Shanghai educational system.

\section{Limitations and future directions}

The data analyzed in the reported study were cross-sectional and collected from self-reports, which do not allow for causal conclusions, in particular for one kind of risk for burnout: organizational justice. The number of participants in this study was small (only 135), as the number of MD students at the Shanghai medical school is generally smaller than that of other medical schools throughout the world. Furthermore, the interns had received only $8-10$ months of medical training. Lastly, some individuals with negative affectivity - especially subjects from this generation of "angry youths" - may have perceived their work context more negatively, which would have artificially strengthened the associations between burnout symptoms and organizational justice.

In order to analyze the effect of the number of years spent in an occupation on burnout, the authors would hope to compare data between intern doctors and staff doctors within the same hospitals in future studies.

\section{Significance}

Burnout is an important barometer of chief dysfunctions in the health care workplace. Though circumscribed in scope

Table 4 Correlation analysis of individual dimensions of organizational justice and job burnout $(n=93)$ from Shanghai school

\begin{tabular}{|c|c|c|c|c|c|c|}
\hline \multirow[t]{2}{*}{$\begin{array}{l}\text { Job burnout/ } \\
\text { organizational } \\
\text { justice }\end{array}$} & \multicolumn{2}{|c|}{$\begin{array}{l}\text { Emotional } \\
\text { exhaustion }\end{array}$} & \multicolumn{2}{|c|}{ Cynicism } & \multicolumn{2}{|c|}{$\begin{array}{l}\text { Reduced } \\
\text { professiona } \\
\text { efficacy }\end{array}$} \\
\hline & $r$ & $P$ & $r$ & $P$ & $r$ & $P$ \\
\hline $\begin{array}{l}\text { Distributive } \\
\text { justice }\end{array}$ & -0.190 & 0.067 & -0.293 & $0.004 *$ & 0.105 & 0.314 \\
\hline Participation & -0.129 & 0.216 & -0.332 & $0.001 * *$ & 0.103 & 0.324 \\
\hline $\begin{array}{l}\text { Complaint } \\
\text { mechanisms }\end{array}$ & -0.150 & 0.150 & -0.226 & $0.029 *$ & 0.054 & 0.602 \\
\hline
\end{tabular}

Notes: $* P<0.05 ; * * P<0.01$. 
and limited by a number of methodological issues, this study contributes to the research on burnout and documents that there was significant burnout morbidity among the participating intern doctors. How should suitable training of interns be promoted and the degree of job burnout be avoided or decreased? Bickel stated that "skills are like muscles, selfefficacy is like sturdy boots, advancement "how-to's" are like maps, and mentors are like trail guides". ${ }^{9}$ This has been true in the past and should continue to be true into the future in modern medicine education. First, medical interns must take the initiative to express their views, regardless of their own work, rotation plans, or exchange of clinical diagnoses and treatment, to improve their working efficiency and enhance their working experience and skills..$^{10-12}$

Interns experienced contradictions with patients, supervisors, society, and medical subspecialty decisions..$^{13,14}$ Therefore, their professional point of view has to mature step by step. Due to heavy physical and psychological pressure and even exhaustion, medical interns may appear to work in an insufficient state and even make some clinical errors, ${ }^{15}$ mainly due to fatigue, depression, decreased enthusiasm, and bias from some patients. ${ }^{16}$ Therefore, understanding psychological burnout and its related factors, and synchronized intervention are essential for medical interns to enhance their psychological energy and improve the quality of their working and learning. ${ }^{10}$

Due to a medical education that was semi-military in its structure (ie, authority was seldom questioned), the interns were reluctant to ask for assistance or give comments, and passively followed instructions from superiors. Also partially results from the environmental factors of organizational justice changes. On other side of the coin, Mirrakhimov et al pointed out simple and serious facts in their article "Physician burnout: an urgent call for early intervention in USA", all being affected by the unpalatable changes in the world's socio-economic situations. ${ }^{16}$

\section{Features of job burnout in medical interns}

The job burnout scale showed that medical interns have a certain degree of job burnout, and mental and physical fatigue. They do not have enough motivation and have no feeling of success, and even sometimes have neglectful attitudes to patients and their working environment, and this may have negative effects on their future occupations. It should be mentioned they often had a negative evaluation of themselves and their medical occupation. Strained physician-patient relationships exist for interns. A high inpatient workload in the high-level university hospitals made the interns feel more exhausted in both body and mind. ${ }^{17}$ Indeed, high rates of medical risks make some medical interns feel no sense of achievement in flourishing city districts. There is also the dire situation observed in some subspecialties (pediatrics, gynecology, and obstetrics), as reported in Taiwan, where there is a profound lack of recruitment of new resident doctors.

\section{Conclusion}

The study reported showed that significant job burnout exists among Chinese medical interns in a university hospital of Shanghai, along with lower psychological health level, and lower professional efficacy. Therefore, burnout may have serious implications not only for the quality of emotional, technical, and general medical care given to patients but also for the health and well-being of the intern doctors themselves. ${ }^{18}$ Organizational justice should be promoted more, and more attention should be paid to medical interns by the university authorities and affiliated hospitals. Medical interns should establish a balanced view of their profession through psychological consultations, occupational lectures, successful clinical practice, and self-maturation. During this transitional phase, they may experience painful and then successful years of work to meet professional training standards.

\section{Acknowledgments}

XPW wishes to thank the medical intern doctors, Drs YM Jiang, WJ Li, and YY Zhou. This study was supported by funding from the Medical Education Innovation Center, Shanghai Jiao Tong University School of Medicine (WXP number 2008013).

\section{Disclosure}

The authors declare no conflicts of interest in this work. The funder mentioned had no role in the design of the study, data collection and analysis, the decision to publish, or the preparation of the manuscript for publication.

\section{References}

1. Maslach C, Leiter MP. Early predictors of job burnout and engagement J Appl Psychol. 2008;93(3):498-512.

2. Li CP, Shi K. The influence of distributive justice and procedural justice on job burnout. Acta Psychologica Sinica. 2003;35(5):677-684.

3. Chambers R. Avoiding burnout in general practice. $\mathrm{Br} J$ Gen Pract. 1993;43(376):442-443.

4. Li XM, Liu YJ. [Job stressors and burnout among staff nurses]. Zhonghua Hu Li Za Zhi. 2000;35(11): 645-649. Chinese.

5. Krousel-Wood M, He J, Booth M, et al. Formal public health education and career outcomes of medical school graduates. PLoS One. 2012;7(6) e39020. 
6. Widyandana D, Majoor G, Scherpbier A. Preclinical students' experiences in early clerkships after skills training partly offered in primary health care centers: a qualitative study from Indonesia. $B M C$ Med Educ. 2012;12:35.

7. Campbell D, Shepherd I, McGrail M, et al. Procedural skills practice and training needs of doctors, nurses, midwives and paramedics in rural Victoria. Adv Med Educ Pract. 2015;6:183-194.

8. Marshfield, MA. Handbook of Organizational Measurement. In: Price JL, Mueller CW, editors. International Journal of Manpower. Pittman; 1986:305-558.

9. Bickel J. Career development as a long-distance hike. J Gen Intern Med. 2009;24(1):118-121.

10. Sluiter JK, van der Beek AJ, Frings-Dresen MH. Medical staff in emergency situations: severity of patient status predicts stress hormone reactivity and recovery. Occup Environ Med. 2003;60(5):373-374; discussion 375.

11. Paré M. Shift work may be hazardous to your health, doctors warned. CMAJ. 1989;141(3):243-244.
12. Shao S, Zhao F, Wang J, et al. The ecology of medical care in Beijing. PLoS One. 2013;8(12):e82446.

13. Thorsen V, Tharp A, Meguid T. High rates of burnout among maternal health staff at a referral hospital in Malawi: A cross-sectional study. BMC Nurs. 2011;10:9.

14. Fiscella K, Epstein RM. So much to do, so little time: care for the socially disadvantaged and the 15-minute visit. Arch Intern Med. 2008; 168(17):1843-1852.

15. Imai H, Nakao H, Tsuchiya M, Kuroda Y, Katoh T. Burnout and work environments of public health nurses involved in mental health care. Occup Environ Med. 2004;61(9):764-768.

16. Mirrakhimov AE, Rimoin LP, Kwatra SG. Physician burnout: an urgent call for early intervention. JAMA Intern Med. 2013;173(8):710-711.

17. Huang J, Yan L, Zeng Y. Facing up to the threat in China. Lancet. 2010; 376(9755):1823.

18. McCullough B, Marton GE, Ramnanan CJ. How can clinician-educator training programs be optimized to match clinician motivations and concerns? Adv Med Educ Pract. 2015;6:45-54.

\section{Publish your work in this journal}

Advances in Medical Education and Practice is an international, peerreviewed, open access journal that aims to present and publish research on Medical Education covering medical, dental, nursing and allied health care professional education. The journal covers undergraduate education, postgraduate training and continuing medical education including emerging trends and innovative models linking education, research, and health care services. The manuscript management system is completely online and includes a very quick and fair peer-review system. Visit http://www.dovepress.com/testimonials.php to read rea quotes from published authors.

Submit your manuscript here: http://www.dovepress.com/advances-in-medical-education-and-practice-journal 